\title{
Measuring Spirituality and Spiritual Emptiness: Toward Ecumenicity and Transcultural Applicability
}

\author{
David Y. F. Ho and Rainbow T. H. Ho \\ University of Hong Kong
}

\begin{abstract}
The authors review Eastern and Western conceptions of spirituality, explicate the spirituality construct and differentiate it from religiosity, propose strategies for achieving ecumenicity and transcultural applicability, and suggest innovative techniques for measuring spirituality and spiritual emptiness. The essential attributes of ecumenical spirituality are that it (a) is concerned with existential or transcendent questions; (b) belongs to the domain of cardinal values underlying all aspects of life; and (c) is self-reflective, and hence metacognitive, in nature. The paths to spirituality are many and are grounded in different values and beliefs across philosophical-religious traditions. However, commonalities may be extracted at a high level of abstraction and with maximal inclusiveness. Thus, the goal of ecumenicity, and hence transcultural applicability, is attainable.
\end{abstract}

Keywords: spirituality, religiosity, alienation, ecumenicity, transcultural applicability

The idea of spirituality was born when the first Homo sapien stumbled on the question, "What will become of me after I am dead?" For humanity, this question has driven the rise of religions, absorbed the intellectual energy of countless thinkers, and shaped the course of its development. It has become the perennial question: Like no other, it compels us to reflect on the time-limited nature of our existence. Spirituality, however, is concerned with much more than death and what happens after death. It informs humanity about the meaning of life and ways of living one's life. Nourished in values in diverse cultures, spirituality represents a distillate of ecumenical wisdom.

Spirituality is central to philosophicalreligious traditions that have informed conceptions of the good life since ancient times (see $\mathrm{Ng}$, Ho, Wong, \& Smith, 2003, for a review of psychological research on the quest for the good life in the East and the West). In contemporary psychology, the language of mental health and psychological well-being has replaced that of

David Y. F. Ho and Rainbow T. H. Ho, Centre on Behavioral Health, University of Hong Kong.

Correspondence concerning this article should be addressed to David Y. F. Ho, Centre on Behavioral Health, University of Hong Kong, G/F, 10 Sassoon Road, Hong Kong. E-mail: dyfho@hkusua.hku.hk the good life; moreover, the place of spirituality in psychological well-being has been left largely vacant. We argue for restoring spirituality to its rightful place in contemporary psychology, to which philosophical-religious traditions remain relevant. In what follows, we can mention only some of the world's major traditions. However, the idea of equifinality, that the same ultimate goal may be reached from different paths, should counter this limitation to some extent.

Despite its vital significance and intellectual appeal, spirituality has not been included in the agenda of researchers until recent decades. The reason is that spirituality is an elusive concept, into which it is extremely difficult to conduct research. The crux of the problem concerns how spirituality is defined and measured. In this article, we confront the elusive concept head on by formulating strategies to measure it. We impose the goal of transcultural applicability on measurement. Our attempt would be a major step toward overcoming problems of measurement that have bedeviled researchers, and thus establish the scientific study of spirituality on more solid ground; it would also give impetus to more transcultural research.

\section{Spirituality East and West}

The paths guided by different Eastern philosophical-religious traditions to attain spiritual- 
ity, or enlightenment, are many. Ho (1995) identifies psychological decentering as a key idea that has contemporary relevance for the attainment of psychological well-being. To be decentered is to facilitate selflessness (which does not mean absence of self). Selflessness is an antidote to egocentrism and fixation. We may glimpse into the mind of the Daoist philosopher Zhuangzi: acting with spontaneity, freedom from fixed ideas, feeling at home in the cosmos, experiencing "losing" or "forgetting" oneself, contemplating the equality of all things and thinking of others as "I." These are among the inner attributes we would expect to find in spiritual persons. These inner attributes may be measured indirectly through a variety of techniques, such as phenomenological description and behavioral observations by researchers or significant others. Likewise, Buddhist ideas of compassion and letting go of attachments speak clearly on the spirituality, and are potentially measurable.

\section{Hedonic Psychology and Subjective Well-Being}

In the West, two major traditions in conceptions of the good life that inform current research in psychology may be identified $(\mathrm{Ng}$ et al., 2003; Ryan \& Deci, 2001). One is based on hedonism, a version of which is utilitarianism. Hedonic psychology (Kahneman, Diener, \& Schwartz, 1999) and subjective well-being research fall within this tradition. The key construct in hedonic psychology is well-being, defined in terms of pleasure versus pain: Happiness is conceived hedonically. In a similar vein, Diener, Lucas, and Oishi (2002) state: "Scientists who study subjective well-being assume that the essential ingredient of the good life is that the person herself likes her life. Subjective well-being is defined as a person's cognitive and affective evaluations of his or her life.... [It] is a broad concept that includes experiencing pleasant emotions, low levels of negative moods, and high life satisfaction" (p. 63). Research in this tradition is essentially reductionistic: Whereas hedonic psychology reduces the good life to well-being, Diener et al. reduce it to an even narrower concept, subjective wellbeing.

Conceptual and methodological problems, as well as cultural biases, are discernible in studies of happiness based on subjective well-being. A central issue concerns how happiness is conceived and measured. We argue that happiness is more encompassing than subjective wellbeing. Consider the Satisfaction With Life scale used to measure main components of subjective well-being, for instance. The scale favors those who show little inclination or capacity to learn from experience and would hence agree with the scale item, "If I could live my life over, I would change almost nothing" (Diener et al., 2002 , p. 70). It does not measure life satisfaction, let alone happiness, contrary to what its authors claim. Dissatisfaction with some aspects of life does not prevent people from feeling happy and grateful for what they already have; it may even propel people to change for the better and eventually lead a happier life.

\section{Eudaemonia}

The other Western tradition is based on eudemonism or eudaemonia, an ethical system that evaluates actions in terms of their capacity to produce happiness. However, happiness is not defined in hedonic terms. Rather, eudaemonia calls for living in accordance with one's daemon or daimon (true self), as when actions are congruent with deeply held values. One would feel intensely alive and authentic, existing as what one truly is. In psychology, empirical research on psychological well-being based on eudaemonia (e.g., Ryff \& Keyes, 1995) has already been generated. Clearly, spirituality is aligned with eudaemonia rather than hedonism. Likewise, conceptions of spirituality in the East resonate with eudaemonia and are, to make a strong claim, alien to hedonism. For instance, the Buddhist belief in the value of suffering would fly in the face of current conceptions of subjective well-being.

Spirituality is not reducible to happiness equated with satisfaction with life or more generally with subjective well-being. Rather, it is characterized by the capacity for depth of feelings, both positive and negative. A spiritual person is not necessarily happy all or most of the time, and may even experience anguish at times. Indeed, we may consider the inability to feel unhappiness or psychic pain (an instance of emotional numbing) as a symptom of spiritual emptiness. As a Chinese adage states, "There is no greater grief than the death of one's heart." 
The attainment of spirituality is a dynamic process in which struggle, change, and transformation are central (see Hill \& Pargament, 2003, for a discussion of religious and spiritual struggles and their linkages to both negative and positive health outcomes). The journey in quest for personal salvation, freedom from attachment, liberation from self-imprisonment, new directions to lead one's life, enlightenment, and the like is arduous; no end may be in sight; despair may be experienced. Along the way, however, hope invites those who take the journey to go on; tranquility, interspersed with intense feelings such as exhilaration and ecstasy may also be experienced. From this perspective, the preoccupation with subjective well-being appears to be a symptom of attempting to expunge unhappiness from humanity's collective consciousness. But true happiness includes the wisdom to embrace unhappiness as part of life. It comes naturally when one is no longer obsessed with pursuing it.

\section{Ecumenicity and Transcultural Applicability}

The goal of transcultural applicability imposes on researchers two key requirements: differentiating spirituality from religiosity, and moving toward ecumenicity. Meeting these requirements is a step toward achieving transcultural applicability. To our knowledge, they have not been met in measures of spirituality presently available. Richards and Bergin state, "We do not know of any objective religious or spiritual self-report measure that is appropriate for non-Christian clients" (p. 196). For nonWestern populations, researchers (e.g., Shek, 2005) typically import measures developed in the United States, thus raising multiple cultural and methodological questions. Accordingly, this article is conceived with the clear intention of transcending religious, ideological, and cultural boundaries to achieve transcultural applicability.

\section{Differentiation From Religiosity}

Paranjpe (1988a) states:

It is useful to refer to a distinction commonly made in India between "spiritual" as opposed to "religious" pursuits.... The word "spiritual" refers to a deeply personal concern about psychological and moral well- being - regardless of the theological, dogmatic, ritualistic, liturgical, magical, or mystical aspects often associated with religious life. The Sanskrit term adhyatmic conveys this sense of the spiritual, and is essentially untranslatable into English. Yoga and Zen are spiritual in this sense, and have little to do with what is called "religion" in the English language (p. 26)

In a similar vein, Ho (1995) makes a distinction between the philosophical and the religious forms of expression in Confucianism, Daoism, Buddhism, and Hinduism. The philosophical refers to the system of thought contained in a corpus of classical texts or scriptures and subsequent commentaries. The religious refers to a later institutional development, avowed to be built on the philosophical tradition bearing the same name, and is characterized by canonizations, elaboration of rites, and administration by organized clergies. These two forms of expression may embody quite divergent, even inconsistent, values. For instance, burning paper money for the dead by self-proclaimed Buddhists seems out of touch with philosophical Buddhism, which is founded on the ontological denial of individual selves or souls.

This distinction may be extended to other traditions and serves as a starting point for differentiating between religiosity and spirituality. Religiosity usually refers to beliefs, sentiments, and practices that are anchored in a particular religion; its expression is often institutional and denominational, as well as personal. Attending church, or going to a temple, is an example of religiosity. Spirituality has no necessary connection with institutional or denominational affiliation. Though not necessarily anchored in a particular religion, spirituality embodies overarching values, meanings, and principles according to which one conducts one's life. It concerns enduring transcendent or existential questions that have been raised in diverse cultures since humanity began reflecting on its own existence and nonexistence.

Authors have expressed different opinions on the inclusive-exclusive relation between religiosity and spirituality. Richards and Bergin (1997) state: "We view religious as a subset of the spiritual. ... Religious expressions tend to be denominational, external, cognitive, behavioral, ritualistic, and public. Spiritual experiences tend to be universal, ecumenical, internal, affective, spontaneous, and private. It is possible to be religious without being spiritual and 
spiritual without being religious" (p. 13). This quotation contains logically inconsistent statements, because to "view religious as a subset of the spiritual" negates the possibility of being religious without being spiritual. Hill and Pargament (2003) state that "spirituality can be understood as a search for the sacred ... This search takes place in a larger religious context" (p. 65). This statement implies that religiosity is more inclusive than spirituality - a reversal of the position taken by Richards and Bergin. Arguing from the standpoint of secular spirituality, Van Ness (1996) states: "Being religious is not a necessary condition for being spiritual" (p. 1).

We view religiosity and spirituality as two overlapping constructs: Logically, this implies that neither is a necessary or sufficient condition for the other. Accordingly, it is possible to be religious without being spiritual or spiritual without being religious, be both, or be neither. More critically, religiosity may carry with it potential perils of dogmatism, cultism, extremism or, worse, fanaticism (see Stern, 2004, for a study of religious militants who kill in the name of God). In contrast, spirituality has inherent immunity to guard itself against these perils, because of its propensity toward humility, contemplativeness, and self-reflection. Exemplars of spirituality (e.g., prophets, mystics, and arhats) may be tormented by self-doubt or guilt; they may be given to self-denial- but not to suicide bombing or other forms of wanton outbound aggression.

\section{Ecumenicity as Universality}

Our conceptualization of spirituality is ecumenical in orientation, not biased toward or anchored in a particular Christian denomination, or even in a particular religion. By ecumenicity, we mean universality, more than merely transcending denominational or religious boundaries. We mean to identify core values and beliefs common to the world's main philosophical-religious traditions that promise to inform research on spirituality. These values and beliefs include the capacity to forbear, even accept, suffering or misfortune; to forgive; to construct and reconstruct meaning; to maintain peace of mind, spirit, and sense of direction, even in the face of misfortune or harsh external circumstances; love of humanity; and so forth.
Richards and Bergin (1997) argue that "a viable spiritual strategy must be ecumenical ... as much as possible" (p. 15). However, their conception of ecumenicity is much narrower in scope than ours. They based their strategy on a theistic worldview, the most important assumptions of which are that God exists, that human beings are the creations of God, that human beings have a spirit or soul, and that there are unseen spiritual processes by which the link between God and humanity is maintained. This is essentially a monotheistic worldview, held by followers of Islam, Judaism, and Christianity (cf. Burke, Chauvin, \& Miranti, 2005, chaps. 13-15). We content that a theistic (monotheistic, polytheistic, or pantheistic), or atheistic, worldview is neither necessary nor sufficient for spirituality.

Van Ness (1996) articulates the case for secular spirituality, without which any claim to universality would be incomplete. However, the idea of atheistic spirituality is likely to arouse strong opposition, rooted in the view that religion and atheism, Marxist atheism in particular, are natural, reciprocal anathemas. Revisiting historical Marxism, is necessary to counter this opposition. As an atheist, Marx assaults religion as the opium of the people, but he never denies the spiritual dimension of human existence (Page, 1993).

Marx contributes to our understanding of spirituality via his description of fetishism and alienation, a concept that has deep roots in the Judeo-Christian tradition. By fetishism, Marx means attributing a "fantastic" quality to commodities, inanimate objects that have been produced by none other than their producer; labor, which can be bought or sold, is also a commodity. This occurs in capitalist societies, where use-value (the usefulness of an object or labor) is separated from exchange-value (the marketplace value of an object or labor). Commodity fetishism obscures social relations, making them appear as relations between inanimate objects instead of between people. In his classic statement of alienation, Marx (1932/1964) describes the human condition of self-estrangement. Devoid of a sense of communality, modern individuals are estranged from one another and from oneself; from their labor and products of their labor; and from nature. Powerlessness in the face of impersonal and inhuman forces dominating their lives, they do not experience 
themselves as agents acting in control of their life-activity. Lack of self-worth and meaninglessness characterize their existence. Moreover, alienation is fundamentally self-alienation, because it is human creative activity itself that has created the conditions, economic in particular, for impersonal (e.g., market) forces over which humanity is powerless to control. Thus, humanity is estranged from its own creativity, from its own essence or nature, because collectively human beings are deprived of actualizing their nature. The Marxist diagnosis of this human condition locates the cause in historicaleconomic forces independent of people's collective will, particularly social injustice in the form of oppression and exploitation. Therefore, it calls for action to defeat social injustice.

Alienation and fetishism may be viewed as negations of spirituality. Marx's concern with these symptoms of spiritual emptiness is as relevant in the 21st as it was in the 19th century. Witness, for instance, the commodity fetishism intensified by commercialization and consumerism in contemporary societies. No wonder, then, debates concerning Marxism and spirituality continue to excite intellectual and academic communities (e.g., Birnbaum, 1993, Part 2; Gottlieb, 1992, pp. 197-222; Page, 1993; Pettman, 2004, Part 3). Restoring Marx to his rightful place in the great spiritual traditions is a step toward ecumenicity. It serves to advance humanistic, action-oriented spirituality, to which the universal ideal of justice for all is inseparable from the individual quest for the meaning of life. It provides a perspective essential for understanding and meeting the spiritual needs of people in Mainland China and postcommunist Russia and Eastern Europe, who have experienced unprecedented tumultuous sociopolitical changes in the last century (see Epstein, Genis, \& Vladiv-Glover, 1999, Part 5, for a postmodern account of Russian spirituality in post-Soviet culture).

In sum, the paths to spirituality are many and are grounded in different beliefs: in selfcultivation, as in Confucianism; in some higher, sacred, or divine objects or beings; in a supreme being (Allah, God); in ultimate reality (e.g., Brahman in Hinduism); in salvation through enlightenment, as in Buddhism; in the Dao (the "Way"). Some beliefs are agnostic, atheistic, or nontheistic in orientation, and are based on humanism, such as a universal ideal (e.g., broth- erhood of humankind) that goes beyond any for the individual. Common to these beliefs is the acknowledgment of human imperfection or limitation and of the existence of some higher being or principle. Spiritual persons, both religious believers and nonbelievers, invest emotional or intellectual energy and attach great significance to values and beliefs from which springs their spirituality.

\section{Strategies for Ecumenicity and Transcultural Applicability}

We propose to adopt two strategies for achieving ecumenicity and transcultural applicability: (a) extracting commonalities at a high level of abstraction across philosophicalreligious traditions, and (b) maximal inclusiveness (or minimal exclusiveness). These strategies have been used in the construction of the Body-Mind-Spirit Well-Being Inventory $(\mathrm{Ng}$, Yau, Chan, Chan, \& Ho, 2005).

Extracting commonalities. The strategy of extracting commonalities begins with taking note of the ecumenical significance of some of the world's great philosophical-religious teachings. For instance, the idea that Buddha nature is inherent in all humankind is ecumenical in orientation. Similarly, the idea of all-embracing Dao serves to transcend barriers both between and within cultures. Thus, attaining spiritual well-being inspired by these teachings is a step toward the eventual realization of ecumenical ideals. No less strong a case can be made for teachings in the West.

This strategy presupposes the existence of core values and precepts shared by different philosophical-religious traditions, although their concrete expressions may take different forms. It entails the identification of these core values and precepts at a high level of abstraction. To illustrate, we may take the case of the Buddhist belief that suffering ceases through selflessness; the moral implication is that, likening others to oneself, one should reduce suffering in others. Its counterpart in Christianity, though not identical, may be discerned. Suffering presents opportunities for acts of courage, forbearance, or kindness, as well as for strengthening one's faith. The exemplar is the suffering of Jesus for the salvation of all humankind. Extraction then results in affirming the spiritual value of suffering, but leaving open what that 
value may contain or entail. For health care workers, this spiritual value has clear implications for how suffering, even as grave as that caused by an incurable disease, may be transformed into a positive force (for evidence on linkages between religiosity/spirituality and health, see Ho, 2005; Ng et al., 2005; Powell, Shahabi, \& Thoresen, 2003; Seeman, Dubin, \& Seeman, 2003).

Apophasis found across philosophicalreligious traditions may serve as another illustration. We begin with an exposition on the Islamic worldview in the light of modern cosmology by physicist Guiderdoni (2002); in particular, the apophatic nature of spiritual knowledge: "The believer discovers that any statement upon God's essence is impossible, according to the Prophetic saying: 'Reflect upon all things, but reflect not upon God's Essence", (p. 146). As are other Islamic beliefs, this apophatic nature of spiritual knowledge is not unique to Islam. In Christianity, a well-known medieval legend about St. Augustine conveys the message that attempting to fathom the mystery of the Holy Trinity is as futile as trying to empty the sea by pouring water into a hole in the sand along the seashore. Epstein (1999) makes the point that, "Ever since the Byzantine period, Eastern Christianity has been home to the tradition of apophatic or negative theology" (p. 347). Apophasis or negation is prominent in Buddhist thought, particularly that of Ch'an (Zen in Japanese) Buddhism; that the Dao cannot be named or expressed in words is central to Daoism; in Hinduism, the Advaita monistic doctrine states that Brahman, the one and only one reality, is without attributes and hence ineffable (Ho, 1995; Paranjpe, 1988b, 1998; cf. Epstein, 1999, pp. 353-354).

Extracting commonalities underlying these apophatic traditions at a high level of abstraction results in an insight into the insuperable limitations of the human mind and, ultimately, the impossibility of comprehending the infinite by the finite. This insight is metacognitive in nature: "I know my inherent limitations." It activates the wisdom to accept human limitations; it is the mother of humility in a deeply spiritual sense, which extends beyond religious into secular spirituality. Thus, we arrive at a formulation that should have high transcultural acceptability: Spiritual growth parallels depth of humility following the discovery and accep- tance of human ignorance and limitations. Again, extraction affirms acceptance and humility as spiritual values, which one may interpret in various ways according to one's cultural orientation and ideological or religious persuasion.

Maximal inclusiveness. This strategy states that a core value or belief originating from one of the world's main philosophical-religious traditions may be accepted into the fold of ecumenical spirituality, if it is not absent, negated, or disavowed in any other. Thus, maintaining inner peace, pursuing truth, striving to reach higher goals, valuing human life, love of humanity, and so forth qualify as spirituality, because to our knowledge they are upheld in all traditions. Universal love is the lodestone of ecumenicity. It finds expression in the Greek idea of agape, the Confucian idea of ren (benevolence), the Buddhist idea of daiai ("large love"), the Christian ideas of caritas and lovefeast. At root, it champions the intrinsic value of human life and cherishing care for one's fellowmen. In contrast, the extension of the regard for human life to all living creatures is specific to Buddhism; atonement for original sin is specific to Christianity. Therefore, these do not qualify for inclusion.

An implication of maximal inclusiveness is that we would not limit spirituality to a theistic worldview, which would exclude large portions of humanity, including those who hold nontheistic (e.g., Confucian), atheistic, or agnostic worldviews (cf. Pettman, 2004, Part 3). Kier and Davenport (2004) deplore the lack of research attention to atheists. Who is to say that espousing a theistic worldview is sufficient for spirituality, or that spiritual experiences are beyond the reach of atheists or agnostics? In a survey on spirituality in Mainland China, Zhang and Ho (2004) obtained written responses from university instructors who taught compulsory courses in Marxism-Leninism and were expected to be atheists. The responses indicated that the overwhelming majority considered spirituality a meaningful, positive value. Interpretations of spirituality varied widely. Only $44 \%$ of respondents flatly denied that there was a relation between spirituality and religion. The important point is that professed atheists do not reject spirituality.

Another group that also demands greater research attention is Muslims. In the United States, Muslims will number second only to 
Christians as a religious group by the year 2010 (Melton, 1993). Islam is the second largest and the fastest growing religion in the world (Esposito, 1999). The upsurge of terrorism and counterterrorism following September 11, 2001, heightens the urgency of ecumenical understanding and dialogues. Between the Islamic and the non-Islamic worlds, mutual misperceptions are rife. It is ironic that the name Islam is derived from the Arabic root word salaama, which means submission, obedience, peace, and purity. In his cultural psychological study of the Middle East, Gregg (2005) attempts to dispel some prominent misunderstandings, for instance: "Islamic 'fatalism' breeds inaction and stalls development," and "Terrorism springs from a vein of fanaticism in Arab culture and the Arab psyche" (p. 13). Religious and spiritual issues in counseling for Muslims are discussed in Burke et al. (2005, Chap. 15) and Kobeisy (2004); information on native healing in ArabIslamic societies may be found in Al-Issa and Al-Subaie (2004).

\section{Construct Explication: Metatheoretical Propositions}

Preceding discussions illustrate that meeting the challenge of measuring spirituality must begin with construct clarification. Accordingly, we formulate a number of metatheoretical propositions to explicate the spirituality construct. Collectively, these propositions make clear that all phenomena pertaining to spirituality are psychological phenomena, but that the converse does not hold; that is, spirituality is a subset of psychological phenomena. Ideally, spirituality should be manifest in thought and action identifiable as distinct from those pertaining to phenomena outside the subset. Unavoidably, however, the boundary of the spirituality subset is fuzzy. The propositions only render it less fuzzy, but they do provide some guidelines for measurement. They form a basis for delineating the defining or essential attributes of ecumenical spirituality. This is a necessary step toward defining a set of inclusion-exclusion criteria, which direct researchers' attention to appropriate target patterns of thought and action. Equally important, they spell out the conditions for a candidate item to qualify as measuring spirituality, or at least a component of it. This helps to constrain overinclusiveness, which would dilute the construct's utility. The metatheoretical propositions are stated as follows:

1. Spirituality addresses existential or transcendent questions, such as those concerning the meaning and purpose of life. Conviction that life is meaningful and purposeful is essential to spirituality.

2. Spirituality belongs to the domain of supraordinate or cardinal values underlying all aspects of life.

3. Spirituality is self-reflective, and hence metacognitive, in nature.

\section{Existential-Transcendent Quest}

Spirituality entails an existential quest for a sense of direction; to answer questions about life and death, being and nonbeing: "What is the meaning of life, where was I before I was born, what becomes of me after I am dead? What makes a good life?" Such a quest precludes automatic falling back on superstitious beliefs, blind faith, religious dogmata for a ready answer; or engaging in religious rituals without examination or reflection. Often, existential quest is characterized by doubt and struggle.

Alienation follows from failures of existential quest: feeling that life is meaningless, purposeless; that questions about life and death are "a waste of time." A symptom is estrangement: An alienated person feels estranged from the world, from others, or from God; a selfalienated person feels estranged from himself. The estranged self feels enslaved; it has no sense of agency. Work, love, and activity stand as masters of the enslaved self, because they seem meaningless. Another symptom of alienation is disorientation, or loss of direction. Disorientation emerged as one of three factors in a study of spirituality ( $\mathrm{Ng}$ et al., 2005).

Transcendence defines one's relationships with oneself, others, society, humanity, nature, and cosmos, and (to religious believers) some higher, divine, sacred, or supreme being or beings. It means understanding the self in a larger context (e.g., self-in-cosmos, personal relationship with God), thus conferring meaning and purpose to one's life. Transcendent experiences may be at once personal and universal. They do not necessarily embody religiosity. The antith- 
esis of transcendence is self-encapsulation, in which the self derives meaning and purpose from its own individual existence, without reference to any larger context (for a discussion, see Ho, 1995; Ho, Peng, Lai, \& Chan, 2001). Self-encapsulation is a form of egoism or selfcontained individualism.

\section{Cardinal Values}

Spirituality lies at the core of a person's value system. It belongs to the domain of supraordinate or cardinal values underlying all aspects of life. A cardinal value may be conceived as a metavalue, that is, a value of values. We may illustrate this idea with the following statements, each of which expresses a metavalue: "I hold the defense of liberty as supreme in my scale of political values," "Spiritual fulfillment is more important to me than sensual or material gratification," and "Nothing is more valuable than human life." It may be seen that each statement asserts a priority among different values.

As a transcendent value, spirituality defines one's relationships with oneself, others, humanity, society, nature, cosmos, and (to believers) the divine, God, or Ultimate Reality. (Thinking about these relationships does not necessarily quality as spirituality; only when the thinking entails the core of one's value system does it qualify.) Viewed in this light, spirituality is the wellspring from which selfhood and identity grow into maturity; it guides the formation of worldviews; it confers meaning and adds color to life.

An implication is that manifest spirituality is best conceived as a pattern of patterns, or metapattern, of thought and action in diverse domains of life. Spirituality should be manifest in not just a compartmentalized domain but in diverse domains of life, such as work, family, and civic performance. We sense inherent irony in describing a person as spiritual on Sundays but not weekdays, at home but not at work, or in treating friends but not strangers.

\section{Self-Reflective Metacognition}

The capacity for self-consciousness is a necessary, but not sufficient, condition for spirituality. Thus, awareness of one's existence does not qualify as an essential aspect of spirituality; awareness of that awareness does. A spiritual person is aware of not only his existence, but also aware that he is aware of it; he is, furthermore, capable of contemplating the frightful consequences of losing his self-awareness or even his being. Such awareness belongs to metacognition, a higher and more complex domain of cognition.

Metacognition is thus vital to the development of spirituality. It enables the self to be aware of its place in the world and to engage in internal dialogues about its relations with both itself and nonself. A self so empowered is what Ho, Chan, Peng, and Ng (2001) term dialogical self. Metacognition is instrumental for the dialogical self to be cognizant of its limitations. That is the mother of humility. Metacognition is also essential for the dialogical self to be aware of its self-awareness, or its nonbeing. (We would argue that awareness of one's selfawareness is a necessary, but not sufficient, condition for awareness of one's nonbeing, which is more cognitively demanding.) It enables the dialogical self to reflect upon the meaning and purpose of its existence; to entertain possibilities of what it may become, never experienced before, in the future. It renders new forms of thought and action possible, and thus confers transformational capabilities upon the dialogical self. In sum, it drives the spiritual self to be engaged in internal dialogues and thus to participate in its own re-creation.

As to its place in the world, the dialogical self has to be aware of a bidirectional process: perceiving how it has been treated by the world and committing itself to actions, reactive or proactive, directed toward the world. It must also deal with tensions that may arise from discrepancies in this bidirectional process (Ho, Peng et al., 2001). People react in different ways to perceptions of ill fortune or misfortunes. Some remain bitter for life, feeling that the world owes them a better deal. Others commit themselves to make the world a better place. Still others, who have been treated with gross injustice by others, let go of their anger and forgive. Therefore, we have reason to say that forgiveness is a component of spirituality.

We may index cognitive complexity in terms of degrees of cognitive construal. Following Ho, Peng et al. (2001), cognitive construals about an object (e.g., oneself) are first-degree construals; metacognitive construals (metacog- 
nition) are second-degree construals; construals of metacognitive construals (metametacognition) are third-degree construals; and so forth ad infinitum. In short, any construal may be itself the object of the next higher degree construal. Examples are "I live from day to day; I don't think about tomorrow" (1st degree); "That means a lack of purpose in life" (2nd degree); "When I realize I lack purpose in life, I become unhappy" (3rd degree). Higher degrees of construal are indicative of greater cognitive complexity, and hence capability. This provides an operational scheme to delineate more precisely the cognitive characteristics of spirituality. To be explicit, we say that spirituality is characterized by higher degree construals.

\section{Meeting the Challenges of Operationalization and Measurement}

Although spirituality is not directly observable, its effects on a person's life in different domains are accessible to observation. These effects may be subjectively felt and selfreported and may be manifest in words and actions noticeable by others, in different domains of life. Different component ideas of spirituality may be identified, thus calling for multidimensional measures. Similarly, the lack or absence of spirituality and, worse, spiritual emptiness are no less measurable (in our view, probably easier). A methodological implication is that we may use construct pairs (e.g., Existential Quest vs. Alienation, Transcendence vs. Self-Encapsulation), with one construct pertaining to a component of spirituality and the other to a corresponding component of spiritual emptiness. This would reduce bias both in looking for something where there is little to be found and in failing to look for something where something can be found. "Spiritual" individuals who meet stringent criteria for spirituality may not be found in abundance; using construct pairs would circumvent this problem. More important, it would facilitate the study of spirituality and its negation as a dynamic process.

It is important to distinguish between dimension and polarity. We view spirituality and spiritual emptiness as multidimensional constructs. However, we do not view these two constructs as reducible to merely opposites of each other; similarly, across components each construct pair is not viewed as polar opposites on a con- tinuum. For instance, Spiritual Fulfillment and Alienation are not construed as merely opposites of each other along the same bipolar continuum; rather, they are better represented on two unipolar continua. This representation allows for the coexistence of spiritual fulfillment and alienation. Again, the methodological advantage is that it facilitates studying spirituality as a dynamic process in which struggle, ups and downs, are reflected.

Components of spirituality and spiritual emptiness, once identified and accepted as candidate items, should be formulated in ways that allow for interpretation and expression in various ways according to one's cultural orientation and ideological or religious persuasion. As emphasized throughout this article, our approach to measurement allows for variation in the grounds of belief and the chosen path in the individual's existential-transcendent quest. However, dismissing the quest as useless or meaningless, refusing to engage in selfreflection, failure to take action, being uncommitted to anything, and the like would be regarded as manifestations of spiritual emptiness.

\section{Overcoming Barriers to Observation}

Barriers to observation, and hence measurement, pose a formidable challenge to researchers. Spiritual experiences (as are those of alienation) are not easily articulated verbally; they may not even be labeled as spiritual by the experiencing person. Many varieties of spiritual experience are esthetically felt in the visual, kinesthetic, or musical, rather than the linguistic, modality. That is why it is often inadvisable not to ask directly and explicitly people to describe their "spiritual experiences." Viewed in this light, paper-and-pencil self-report questionnaires are particularly suspect.

In any case, spirituality (or spiritual emptiness) is privately experienced, as are other psychological phenomena (Ho, in press); to many, it is highly personal, not to be revealed to others easily. If spirituality is known only to the private self, then logically it is excluded from the public domain. As Ho, Fu, and $\mathrm{Ng}$ (2004) argue, however, private experiences are not entirely private. The circumstances that induce private experiences, the ways in which they are construed and expressed, and the consequences that follow from their expression may not be private 
at all. There is no necessity for the composition of "others" to remain constant. Furthermore, the private self changes as a function of the quality of self-other relations. Thus, given the right conditions, private spiritual experiences may be revealed to or perceived by others.

Eastern philosophical-religious traditions speak of transcendent consciousness, achieved through negating the dichotomy between selfas-subject and self-as-object in different ways (Ho, 1995; Ho, Peng et al., 2001; Paranjpe, 1988b, 1998). We encounter here what appears to be an insurmountable barrier to external observation: Transcendent consciousness is privately experienced and cannot be publicly demonstrated. However, physiological correlates of transcendent consciousness are publicly demonstrable (see Seeman et al., 2003, for a review of the evidence). Transcendent experiences may be reported to a public audience. Their effects, if any, on the lives of people who experience them are potentially measurable. Dreams too offer an opportunity to glimpse, if only indirectly, into the elusive self-assubject (Ho, Chan, et al., 2001; Ho, Peng, et al., 2001). In short, although the workings of the process in which consciousness, transcendent or otherwise, is experienced elude direct observation, the products of this process are accessible to external observation. A challenge to investigators is to differentiate "levels of transcendent consciousness" and their correlates, physiological, psychological, and behavioral. But even a successful demonstration does not validate the claim that the subject-object duality vanishes at a high level of transcendent consciousness. The idea that "only a Buddha knows a Buddha" suggests a plausible approach: comparing notes among accomplished meditators who claim to have experienced nonduality; or, better still, examination of each meditator by a panel of other meditators. This approach may be generalized to render public what would otherwise be private experiential verification: Claims of heightened, unusual spiritual experiences by an individual may be subject to examination as to their authenticity or inauthenticity by a panel of judges who are publicly acknowledged as having had such experiences.

\section{Need for Innovative Techniques}

Methodological implications follow from these considerations. We need to spell out how innovative techniques may be developed to overcome difficulties inherent in measuring the spirituality construct. Researchers have relied almost exclusively on paper-and-pencil selfreport measures (Hill \& Pargament, 2003, p. 70). We have serious doubts about whether such measures are capable of reflecting the richness and complexity of spirituality. Self-report measures are especially problematic in Asian cultures that put a premium on modesty and humility, which would inhibit respondents against attributing to themselves socially desirable characteristics (Chiu \& Yang, 1987). Such measurement problems are by no means limited to Asian cultures, however. As Peterson and Park (2004), who favor self-report measures, noted, "Almost by definition, strengths such as authenticity and bravery are not the sort of traits individuals usually attribute to themselves . . Modesty and humility have eluded reliable assessment" (p. 429). Not surprisingly, the Values in Action Inventory of Strengths developed by Peterson and Park (2004), a self-report measure of strengths of character, has rather low correlations (around 0.3), with nomination of strengths by friends or family members (p. 442).

Another limitation of self-report measures is their inability to assess heightened esthetic sensibilities that are deeply felt but defy verbal description-especially if they are experienced in nonlinguistic modalities, visual, kinesthetic, musical. Heightened esthetic sensibilities in a spiritual experience touch the core of one's being: The majesty of nature, the vastness of the cosmos, artistic expressions, and beauty in all its variegated forms are esthetically felt; deep emotions are evoked. Lowen (1990) speaks of the spirituality of the body: a harmony of body, mind, and emotions that he calls the "state of grace." The challenge to measurement is to capture nonlinguistic spiritual experiences (for a coverage of music and spirituality, see Lewis, 2002, Chap. 10, "Spirituality, Music, and Laughter"; Lipe, 2002). Using nonverbal measures, such as drawings (e.g., Pendleton, Cavilli, Pargament, \& Nasr, 2002), is especially suitable for children.

Given the formidable challenges to measurement already discussed, we argue for relying more on (a) qualitative, open-ended, experience-near techniques (see Hodge, 2001, for a review of qualitative methods of assessment); personal diaries, phenomenological accounts (e.g., Ho, in press); (b) nonverbal, expressive 
measures (e.g., music appreciation, drawings, movement analysis); (c) life histories, clinical or observational data, peer reports, reports by significant others; and (d) videotaped information, narrative analysis, thematic categorization and coding for content analysis. Physical correlates or effects of spirituality may be measured by physiological data (e.g., salivary cortisol, as in the study by Ho, 2005), indices of brain function, physical health status, and medical records.

\section{Conclusions}

Our major conclusions may be summarized as follows:

1. Both Eastern and Western conceptions of spirituality are aligned with eudaemonia rather than hedonism.

2. Spirituality and religiosity are overlapping constructs; accordingly, it is possible for a person to be religious without being spiritual or spiritual without being religious, be both, or be neither. Differentiation between the two constructs is essential to transcultural applicability.

3. A theistic or atheistic worldview is neither necessary nor sufficient for spirituality. The paths to spirituality are many and are grounded in different values and beliefs across philosophical-religious traditions. However, commonalities may be extracted at a high level of abstraction and with maximal inclusiveness. Thus, the goal of ecumenicity, and hence transcultural applicability, is attainable.

4. Spirituality (a) is concerned with existential or transcendent questions; (b) belongs to the domain of cardinal values underlying all aspects of life; and (c) is selfreflective, and hence metacognitive, in nature. This proposition defines the essential attributes of ecumenical spirituality.

5. To meet challenges to measurement and operationalization, we urge using (a) multidimensional measures to reflect the effects of spirituality in different domains of life; (b) construct pairs to reflect the dynamics of spirituality and spiritual empti- ness; (c) items that allow for interpretation and expression in various ways according to one's cultural, ideological, or religious persuasion; and (d) innovative (e.g., qualitative, open-ended, experience-near, nonverbal, expressive) techniques to reduce the current overreliance on self-report measures.

Measuring spirituality is difficult; measuring spirituality with transcultural applicability is even more so. In the article, we have endeavored to show how it may be done. We have also identified serious lacunae of knowledge. Psychological research on spirituality involving two groups, Muslims and atheists, is virtually nonexistent. The case of Muslims highlights the urgent need to counter biases against specific groups, cultural, ethnic, or religious, and for interfaith dialogues. The case of atheists compels us to engage in a thorough reexamination of the theistic foundation of spirituality that has dominated research. More generally, the amount of research conducted across cultural, religious, or ethnic groups is uneven, to say the least: The bulk of research has involved Christians, leaving most of the rest untouched. This state of affairs is inexcusable at a time when psychologists have been subject to the siren calls for greater sensitivity to gender, ethnic, and cultural issues. Without a fundamental reordering of priorities in the research agenda, claims of ecumenicity would sound hollow.

\section{References}

Al-Issa, I., \& Al-Subaie, A. (2004). Native healing in Arab-Islamic societies. In U. P. Gielen, J. M. Fish, \& J. G. Draguns (Eds.), Handbook of culture, therapy, and healing (Chapter 19, pp. 343-366). Mahwah, NJ: Erlbaum.

Birnbaum, N. (1993). Searching for the light: Essays on thought and culture. New York: Oxford University Press.

Burke, M. T., Chauvin, J. C., \& Miranti, J. G. (2005). Religious and spiritual issues in counseling: Applications across diverse populations. New York: Brunner-Routledge.

Chiu, C. Y., \& Yang, C. F. (1987). Chinese subjects' dilemmas: Humility and cognitive laziness as problems in using rating scales. Bulletin of the Hong Kong Psychological Society, 18, 39-50.

Diener, E., Lucas, R. E., \& Oishi, S. (2002). Subjective well-being: The science of happiness and life 
satisfaction. In C. R. Synder \& S. J. Lopez (Eds.), Handbook of positive psychology (pp. 63-73). Oxford, England: Oxford University Press.

Epstein, M. N. (1999). Post-atheism: From apophatic theology to "minimal religion." In S. Vladiv-Glover (Trans. and Ed.), Russian postmodernism: New perspectives on post-Soviet culture (pp. 345-393). New York: Berghahn Books.

Epstein, M. N., Genis, A. A., \& Vladiv-Glover, S. (1999). In S. Vladiv-Glover (Trans. and Ed.), Russian postmodernism: New perspectives on postSoviet culture. New York: Berghahn Books.

Esposito, J. (1999). The Islamic threat. Oxford, England: Oxford University Press.

Gottlieb, R., S. (1992). Marxism, 1844-1990: Origins, betrayal, rebirth. New York: Routledge.

Gregg, G. S. (2005). The Middle East: A cultural psychology. New York: Oxford University Press.

Guiderdoni, B. (2002). The Islamic worldview and modern cosmology. In W. M. Richardson (Ed.), Science and the spiritual quest: New essays by leading scientists (pp. 133-148). Florence, KY: Routledge.

Hill, P. C., \& Pargament, K. I. (2003). Advances in the conceptualization and measurement of religion and spirituality: Implications for physical and mental health research. American Psychologist, 58, 64-74.

Ho, D. Y. F. (1995). Selfhood and identity in Confucianism, Taoism, Buddhism, and Hinduism: Contrasts with the West. Journal for the Theory of Social Behaviour, 25, 115-139.

Ho, D. Y. F., Chan, S. F., Peng, S. Q., \& Ng, A. K. (2001). The dialogical self: Converging East-West constructions. Culture and Psychology, 7, 393408.

Ho, D. Y. F., Fu, W., \& Ng, S. M. (2004). Guilt, shame, and embarrassment: Revelations of face and self. Culture and Psychology, 10, 159-178.

Ho, D. Y. F., Peng, S. Q., Lai, A. C., \& Chan, S. F. (2001). Indigenization and beyond: Methodological relationalism in the study of personality across cultures. Journal of Personality, 69, 925-953.

Ho, R. T. H. (2005). Psychophysiological effects of psychosocial interventions: An example of breast cancer patients in Hong Kong. Unpublished $\mathrm{PhD}$ thesis, University of Hong Kong.

Ho, R. T. H. (in press). The pains and rewards of intercultural fertilization: An interview with David Yau Fai Ho. In P. U. Gielen (Ed.), Conversations with international psychologists. Greenwich, CT: Information Age Publishing.

Hodge, D. R. (2001). Spiritual assessment: A review of major qualitative methods and a new framework for assessing spirituality. Social Work, 46, 203214.
Kahneman, D., Diener, E., \& Schwartz, N. (Eds.). (1999). Well-being: The foundations of hedonic psychology. New York: Russell Sage Foundation.

Kier, F. J., \& Davenport, D. S. (2004). Unaddressed problems in the study of spirituality and health. American Psychologist, 59, 53-54.

Kobeisy, A. N. (2004). Counseling American Muslims: Understanding the faith and helping the people. Westport, CT: Praeger.

Lewis, M. K. (2002). Multicultural health psychology: Special topics acknowledging diversity. Boston: Allyn \& Bacon.

Lipe, A. W. (2002). Beyond therapy: Music, spirituality, and health in human experience: A review of the literature. Journal of Music Therapy, 39, 209240.

Lowen, A. (1990). Spirituality of the body: Bioenergetics for grace and harmony. Riverside, $\mathrm{NJ}$ : Simon \& Schuster.

Marx, K. (1964). The economic and philosophical manuscripts of 1844. New York: International Publishers. (Released by Soviet researchers 1932)

Melton, J. G. (1993). Encyclopedia of American religions (4th ed.). Detroit, MI: Gale Research.

Ng, A. K., Ho, D. Y. F., Wong, S. S., \& Smith, I. (2003). In search of the good life: A cultural odyssey in the East and West. Genetic, Social, and General Psychology Monographs, 129, 317-363.

Ng, S. M., Yau, J. K. Y., Chan, C. L. W., Chan, C. H. Y., \& Ho, D. Y. F. (2005). The measurement of body-mind-spirit well-being: Toward multidimensionality and transcultural applicability. Journal of Social Work in Health Care, 41, 33-52.

Page, B. B. (Ed.). (1993). Marxism and spirituality: An international anthology. Westport, CT: Bergin \& Garvey.

Paranjpe, A. C. (1988a). Introduction. In A. C. Paranjpe, D. Y. F. Ho, \& R. W. Rieber (Eds.), Asian contributions to psychology (pp. 1-50). New York: Praeger.

Paranjpe, A. C. (1988b). A personality theory according to Vedanta. In A. C. Paranjpe, D. Y. F. Ho, \& R. W. Rieber (Eds.), Asian contributions to psychology (pp. 185-213). New York: Praeger.

Paranjpe, A. C. (1998). Self and identity in modern psychology and Indian thought. New York: Plenum Press.

Pendleton, S. M., Cavilli, K. S., Pargament, K. I., \& Nasr, S. (2002). Spirituality in childhood with cystic fibrosis: A qualitative study. Pediatrics, 109, $1-11$.

Peterson, C., \& Park, N. (2004). Classification and measurement of character strengths: Implications for practice. In P. A. Linley \& S. Joseph (Eds.), Positive psychology in practice (pp. 433-446). New Jersey: Wiley. 
Pettman, R. (2004). Reason, culture, religion: The metaphysics of world politics. New York: Palgrave Macmillan.

Powell, L. H., Shahabi, L., \& Thoresen, C. E. (2003). Religion and spirituality: Linkages to physical health. American Psychologist, 58, 36-52.

Richards, P. S., \& Bergin, A. E. (1997). A spiritual strategy for counseling and psychotherapy. Washington, DC: American Psychological Association.

Ryan, R. M., \& Deci, E. L. (2001). On happiness and human potentials: A review of research on hedonic and eudaimonic well-being. Annual Review of Psychology, 52, 141-166.

Ryff, C. D., \& Keyes, C. L. M. (1995). The structure of psychological well-being revisited. Journal of Personality and Social Psychology, 69, 719-727.

Seeman, T. E., Dubin, L. F. \& Seeman, M. (2003). Religiosity/spirituality and health: A critical review of the evidence for biological pathways. American Psychologist, 58, 53-63.
Shek, D. T. L. (2005). A longitudinal study of Chinese cultural beliefs about adversity, psychological well-being, delinquency and substance abuse in Chinese adolescents with economic disadvantage. Social Indicators Research, 71, 385-409.

Stern, J. (2004). Terror in the name of God: Why religious militants kill. New York: HarperCollins.

Van Ness, P. H. (Ed.). (1996). Spirituality and the secular quest. New York: Crossroad Publishing.

Zhang, X. D., \& Ho, D. Y. F. (2004). Responses to a questionnaire on spirituality by university teachers who are professed atheists in Mainland China. Unpublished manuscript, Zhongshan University, Guangzhou, Guangdong, People's Republic of China.

Received March 21, 2006

Revision received May 15, 2006

Accepted June 5, 2006 